\title{
Optimization of Nano Calcium Carbonate Production Process Using Taguchi Method
}

\author{
Gh. Tahmasebi Pour and S. M. Mirzaee Moghadam
}

\begin{abstract}
This paper presents optimization of nano calcium carbonate production parameters to achieve the optimum production rate by using Taguchi method. The combination of optimum level of process parameters was obtained by using the analysis of signal-to-noise $(\mathrm{S} / \mathrm{N})$ ratio. The level of importance of the process parameters on production rate was determined by using analysis of variance (ANOVA). It was found that the optimum level of process parameters are solution flow rate of 9 lit/min, gas flow rate of $20 \mathrm{lit} / \mathrm{min}$, and solution concentration of $70 \mathrm{gr} / \mathrm{lit}$ within the range of experiments and the process parameters in terms of impact significance were found to be gas flow rate, solution concentration, and solution flow rate, respectively. By using the optimum level of the process parameters, the production rate was enhanced by $168 \%$ in comparison to the mean value of the experimental results.
\end{abstract}

Index Terms-Calcium carbonate, nano calcium carbonate, taguchi method, rotation packed bed.

\section{INTRODUCTION}

With development of nanotechnology, nanopowders have found wide and diverse applications in many industries such as electronics, pharmaceutics, optics, ceramics, paper, and chemical and metallurgical industries. Unique properties of calcium carbonate nanopowder make it applicable in different industries such as pharmaceutics, cosmetics, paint, and composite industry.

One of the applied methods used for calcium carbonate nanopowder production is the high gravity reactive precipitation (HGRP) process. HGRP technology creates a high centrifugal gravity environment up to several hundred times greater than the earth's gravity using a rotating packed bed (RPB) system. This system was invented by Ramshaw and Mallinson in 1981 [1] as a gas-liquid contactor. In a high gravity environment, the liquid is uniformly distributed within the RPB and interacted with the gas stream well. The HGRP has a wide application in gas-liquid-solid, gas-liquid, and liquid-liquid multiphase reaction systems such as absorption [2]-[12], distillation [13], [14], deaeration [14]-[19], stripping [20]-[23], ozone oxidation [24]-[27], and reactive precipitation for nanoparticles synthesis [28].

To author's knowledge, effects of nano calcium carbonate production parameters in HGRP method such as the solution

Manuscript received July 7, 2013; revised August 26, 2013.

Gh. Tahmasebi Pour is with the Faculty of New Sciences and Technologies, University of Tehran, Tehran, Iran (e-mail: tahmasebipour@ ut.ac.ir).

S. M. Mirzaee Moghadam is with the Mechanical Engineering Department, Islamic Azad University-Science and Research Branch, Arak, Iran (e-mail: tahmasebi84@yahoo.com). flow rate, gas flow rate, and the solution concentration on the nano calcium carbonate production rate and optimization of these parameters to achieve the optimum production rate have not been studied until now. In this research work, by studying the effects of the nano calcium carbonate production parameters on the production rate using the Taguchi method, the optimum level of production parameters and their priority for achieving optimum production rate have been investigated.

In the next section, experimental procedure will be discussed. Section III contains process optimization by employing Taguchi method. Section IV has been dedicated to analysis of experimental results. Confirmation experiment will be discussed in Section $\mathrm{V}$ and finally the concluding remarks will be given in Section VI.

\section{EXPERIMENTAL PROCEDURE}

The high gravity reactive precipitation (HGRP) process was used to produce the nano calcium carbonate in this research. Fig. 1 shows schematic diagram of the experimental set-up used for the nano calcium carbonate production.

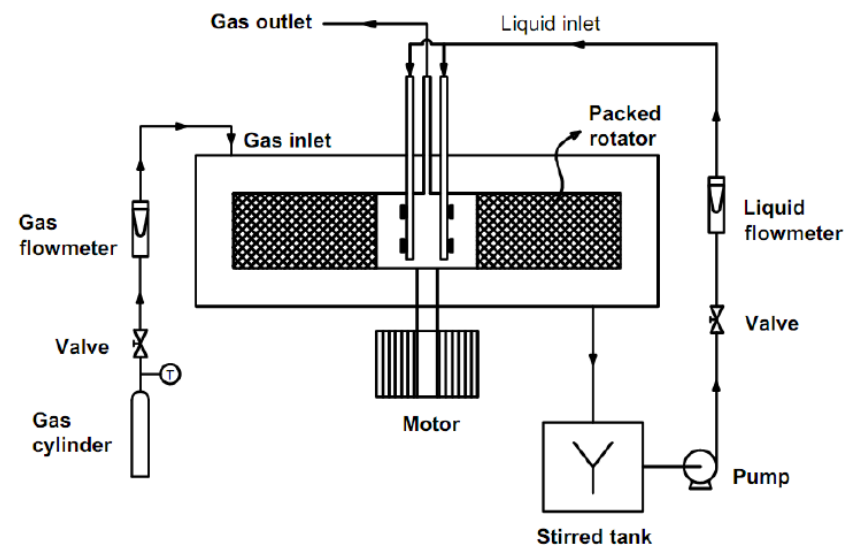

Fig. 1. Schematic diagram of the experimental set-up used for the nano calcium carbonate production.

As shown in Fig. 1, the main part of this system is a packed rotator that has been installed inside a stationary casing. It rotates at a speed of several thousand rpm. Liquid (calcium hydroxide in deionized water solution) is sprayed into the inside edge of the packed rotator via a slotted pipe connected to the liquid inlet. The liquid flows in the radial direction under centrifugal force, passing outward the packing and finally leaves the RPB through the liquid outlet. $\operatorname{Gas}\left(\mathrm{CO}_{2}\right)$ is introduced from the outer edge of the packed rotator to flow inward counter currently against the liquid in the packing, and finally leaves the RPB via the gas outlet.

Calcium hydroxide in deionized water solution and $\mathrm{CO}_{2}$ 
was used as raw materials to synthesis the nano calcium carbonate in a gas-liquid-solid reactant system. The reaction equation can be written as:

$$
\mathrm{Ca}(\mathrm{OH})_{2}(\mathrm{~s})+\mathrm{CO}_{2}(\mathrm{~g})+\mathrm{H}_{2} \mathrm{O}(\mathrm{l}) \rightarrow \mathrm{CaCO}_{3}(\mathrm{~s})+2 \mathrm{H}_{2} \mathrm{O}(\mathrm{l})
$$

\section{Process Optimization By Using TAguchi Method}

TABLE I: ORTHOGONAL ARRAY OF EXPERIMENTS AND THEIR RESULTS (LOWEST VALUE OF INPUT PARAMETERS COINCIDE WITH LOWEST LEVEL OF THOSE PARAMETERS)

\begin{tabular}{cccccc}
\hline $\begin{array}{c}\text { Expt. } \\
\text { No. }\end{array}$ & $\begin{array}{c}\mathbf{R}_{\mathbf{S}} \\
\text { (lit/min) }\end{array}$ & $\begin{array}{c}\mathbf{R}_{\mathbf{G}} \\
(\mathbf{l i t} / \mathbf{m i n})\end{array}$ & $\begin{array}{c}\mathbf{C}_{\mathbf{S}} \\
(\mathbf{g r} / \mathbf{l i t})\end{array}$ & $\begin{array}{c}\mathbf{R}_{\mathbf{P}} \\
(\mathbf{g r} / \mathbf{h})\end{array}$ & $\begin{array}{c}\text { S/N ratio } \\
(\mathbf{d B})\end{array}$ \\
\hline 1 & 2 & 3 & 10 & 660.5 & 56.3976 \\
2 & 2 & 10 & 40 & 1367 & 62.7152 \\
3 & 2 & 20 & 70 & 1582.6 & 63.9872 \\
4 & 5 & 3 & 40 & 787.5 & 57.9250 \\
5 & 5 & 10 & 70 & 2180.9 & 66.7728 \\
6 & 5 & 20 & 10 & 1339.6 & 62.5392 \\
7 & 9 & 3 & 70 & 1710.5 & 64.6624 \\
8 & 9 & 10 & 10 & 1416.5 & 63.0242 \\
9 & 9 & 20 & 40 & 2354 & 67.4361 \\
\hline
\end{tabular}

Taguchi method [29]-[33] is a quite effective way to deal with responses dependent upon multi-variables. This method is a powerful tool for design of experiments and provides a simple, efficient and systematic approach to determine optimum process parameters. Compared with the conventional approach, this method reduces drastically the number of experiments that are required to model the response functions. Traditional experimentation involves variation of one-factor-at-a-time, wherein the rest are held constant. For studying the individual effects of all factors, a lot of time and money must be spent. Taguchi technique overcomes all these drawbacks. In this method, the main effect is defined as the average value of the response function at a particular level of a parameter. The effect of a factor level is the deviation it causes from the overall mean response. The Taguchi method was devised for process optimization and identification of optimum combinations of factors for given responses. The steps involved in the Taguchi method are depicted as follow:

1) Identifying the main functions and the process parameters to be evaluated.

2) Determination of the number of levels for the process parameters.

3) Selecting the appropriate orthogonal array and assigning the process parameters to the orthogonal array and conducting the experiments accordingly.

4) Studying the experimental results by analysis of signal-to-noise $(\mathrm{S} / \mathrm{N})$ ratios to determine the optimum level of process parameters.

5) Investigating the results by analysis of variance (ANOVA) to identify the significance level of the process parameters on the main function.

6) Verifying the optimum process parameters through a confirmation experiment.

In this research, production rate taken as the main function of the nano calcium carbonate production process. The most important influencing parameters on the production rate are the solution flow rate $\left(\mathrm{R}_{\mathrm{S}}\right)$, gas flow rate $\left(\mathrm{R}_{\mathrm{G}}\right)$, and the solution concentration $\left(\mathrm{C}_{\mathrm{S}}\right)$.

Regarding Taguchi quality design concept, process parameters, $\mathrm{R}_{\mathrm{S}}, \mathrm{R}_{\mathrm{G}}$, and $\mathrm{C}_{\mathrm{S}}$ were defined in 3 levels and an $\mathrm{L}_{9}$ orthogonal array table was chosen for the experiments as shown in Table I. The experiments were conducted according to the selected orthogonal array. The calculated values of the production rates $\left(R_{P}\right)$ are given in Table $I$.

\section{EXPERIMENTAL RESUlTS ANALYSIS AND DISCUSSION}

\section{A. Analysis of Signal-to-Noise Ratio}

Based on Taguchi method [29]-[33], optimum level of process parameters is determined by analysis of $\mathrm{S} / \mathrm{N}$ ratio. There are several categories of performance characteristics in the analysis of the $\mathrm{S} / \mathrm{N}$ ratio as lower is better (LB), nominal is best (NB) and higher is better (HB). Since production rate of the nano calcium carbonate should be as high as possible, the higher is better (HB) was selected for obtaining optimum level of process parameters. The $\mathrm{S} / \mathrm{N}$ ratio can be calculated as a logarithmic transformation of the loss function. For HB, the $\mathrm{S} / \mathrm{N}$ ratio can be expressed as:

$$
\eta=-10 \log _{10}\left(\frac{1}{n} \sum_{i=1}^{n} \frac{1}{y_{i}^{2}}\right)
$$

where $y_{i}$ is the response of the ith experiment and $n$ is the repetition of each experiment. Regardless of the category of the performance characteristic, a larger $\mathrm{S} / \mathrm{N}$ ratio corresponds to a better performance characteristic. Therefore, the optimum level of the process parameters is the level with the highest $\mathrm{S} / \mathrm{N}$ ratio. The $\mathrm{S} / \mathrm{N}$ ratios of $\mathrm{L}_{9}$ experiments are shown in Table I. As an example, the calculation of $\mathrm{S} / \mathrm{N}$ ratio for experiment No. 1 is as follows:

$$
\eta=-10 \log _{10}\left(\frac{1}{660.5^{2}}\right)=56.3976
$$

The mean of $\mathrm{S} / \mathrm{N}$ ratio values for a process parameter in a defined level is determined by using the $\mathrm{S} / \mathrm{N}$ ratio values given in Table I. For example the mean value of $\mathrm{S} / \mathrm{N}$ ratios for $\mathrm{R}_{\mathrm{S}}$ in level 1 is:

$$
\frac{1}{3}(56.3976+62.7152+63.9872)=61.03 d B
$$

Fig. 2 (A-C) shows the mean value of $\mathrm{S} / \mathrm{N}$ ratio against different levels of $\mathrm{R}_{\mathrm{S}}, \mathrm{R}_{\mathrm{G}}$, and $\mathrm{C}_{\mathrm{S}}$ parameters. According to the results shown in Fig. 2, it can be concluded that:

1) Increase of solution flow rate $\left(R_{S}\right)$ to 9 lit/min improves the production rate $\left(R_{P}\right)$. Consequently, the best level of $\mathrm{R}_{\mathrm{S}}$ for optimization of the production rate is $9 \mathrm{lit} / \mathrm{min}$ (level 3) within the range of experiments.

2) Increase of the gas flow rate $\left(R_{G}\right)$ to $20 \mathrm{lit} / \mathrm{min}$ causes increase of the production rate again. Therefore the best gas flow rate is $20 \mathrm{lit} / \mathrm{min}$ (level 3) within the range of 
experiments.

3) Increase of the solution concentration $\left(\mathrm{C}_{\mathrm{S}}\right)$ to $70 \mathrm{gr} / \mathrm{lit}$ gives rise to a better production rate. Therefore, the best level of the solution concentration for optimization of the production rate is about $70 \mathrm{gr} / \mathrm{lit}$ (level 4) within the range of experiments.

Based on the mentioned conclusions, it is found that the best level of $\mathrm{R}_{\mathrm{S}}, \mathrm{R}_{\mathrm{G}}$, and $\mathrm{C}_{\mathrm{S}}$ to achieve optimum production rate is level 3 .

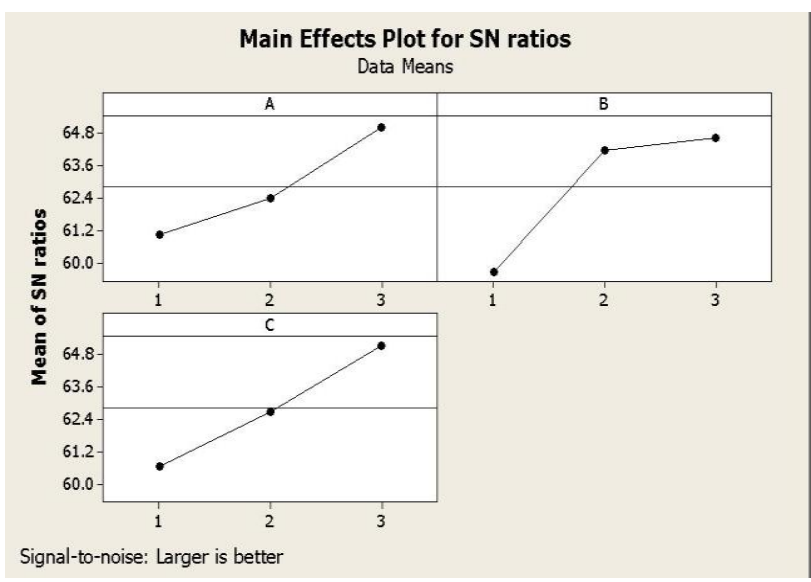

Fig. 2. Effect of different levels of process parameters on $S / N$ ratio: A) $R_{S}, B$ ) $\mathrm{R}_{\mathrm{G}}$, and C) $\mathrm{C}_{\mathrm{S}}$

\section{B. Analysis of Variance (ANOVA)}

The analysis of variance (ANOVA) is used to discuss the relative importance of process parameters on the production rate. The ANOVA is based on the following factors [29]:

- Degree of freedom $(f): f$ denotes the number of independent variables and is calculated as:

$$
f_{T}=N-1, f_{p}=L_{p}-1, f_{e}=f_{T}-\sum f_{p}
$$

where $f_{T}$ is the total degree of freedom, $N$ is the total number of experiments, $f_{p}$ is the degree of freedom for each parameter, $L_{p}$ is the number of levels for the parameter, and $f_{e}$ is the degree of freedom for error.

- Sum of squares $(S S): S S_{T}, S S_{p}$, and $S S_{e}$ denote the total sum of squares, the sum of squares for each parameter, and the sum of squares of the error correlated to all parameters, respectively.

$$
\begin{gathered}
S S_{T}=\sum_{i=1}^{m} \eta_{\mathrm{i}}^{2}-\frac{1}{m}\left(\sum_{i=1}^{m} \eta_{i}\right)^{2} \\
S S_{p}=\frac{1}{n} \sum_{j=1}^{n}\left(S_{\eta j}\right)^{2}-\frac{1}{m}\left(\sum_{i=1}^{m} \eta_{i}\right)^{2} \\
S S_{e}=S S_{T}-\sum S S_{p}
\end{gathered}
$$

where $\eta_{i}$ is the $S / N$ ratio of ith experiment, $m$ is the total number of experiments, $n$ is the repetition of each level of the parameter, $S_{\eta j}$ is the sum of the $S / N$ ratio involving the parameter and level $j$ (Table I).

- Variance $(V)$ : The variance related to each parameter $\left(V_{p}\right)$ and the variance of error $\left(V_{e}\right)$ is defined as follows:

$$
V_{p}=\frac{S S_{p}}{f_{p}}, V_{e}=\frac{S S_{e}}{f_{e}}
$$

- F-ratio $(F)$ : The F-ratio of each parameter $\left(F_{p}\right)$ is given by

$$
F_{p}=\frac{V_{p}}{V_{e}}
$$

- Percentage of the contribution $\left(P_{p}\right): P_{p}$ denotes the percentage of the total variance of each individual parameter.

$$
p_{p}(\%)=\frac{S S_{p}}{S S_{T}} \times 100
$$

The results obtained from ANOVA of $\mathrm{S} / \mathrm{N}$ ratios are shown in Table II. Greater $F$ value and percentage contribution $\left(P_{p}\right)$ for a parameter determine higher impact of the parameter on the production rate. Considering the ANOVA results given in Table II, the process parameters can be ranked in terms of their impact on the production rate as gas flow rate $\left(\mathrm{R}_{\mathrm{G}}\right)$, solution concentration $\left(\mathrm{C}_{\mathrm{S}}\right)$, and the solution flow rate $\left(R_{S}\right)$, respectively.

TABLE II: ANALYSIS OF VARIANCE FOR S/N RATIOS OF PRODUCTION RATE

\begin{tabular}{cccccc} 
Source & $\mathbf{f}$ & $\mathbf{S S}$ & $\mathbf{V}$ & $\mathbf{F}$ & $\mathbf{P}_{\mathbf{p}}(\boldsymbol{\%})$ \\
\hline $\mathbf{R}_{\mathbf{S}}$ & 2 & 24.872 & 12.436 & 3.90 & 23.2385 \\
$\mathbf{R}_{\mathbf{G}}$ & 2 & 45.491 & 22.746 & 7.13 & 42.5034 \\
$\mathbf{C}_{\mathbf{S}}$ & 2 & 30.286 & 15.143 & 4.75 & 28.2970 \\
\hline Error & 2 & 6.381 & 3.191 & & 5.9619 \\
\hline Total & 8 & 107.029 & & & 100 \\
\hline
\end{tabular}

\section{CONFIRMATION EXPERIMENT}

In the Taguchi method, after the optimum level of the process parameters is determined, the final step is to verify the improvement of the performance characteristic using the optimum level of the process parameters. The confirmation experiment was conducted by using the optimum level of the process parameters. The production rate of $2502.72 \mathrm{gr} / \mathrm{h}$ was achieved in this experiment. The improvement of the S/N ratio was $5.1394 \mathrm{~dB}$ and the production rate was enhanced by 1.68 times in comparison to the mean value of the experimental results shown in Table II. These results confirmed the capability of the Taguchi method used for optimizing the production rate.

\section{CONCLUSION}

The most important parameters that govern production process of nano calcium carbonate are the solution flow rate, gas flow rate, and the solution concentration. For optimization of the nano calcium carbonate production rate, the effects of process parameters were studied by using 
Taguchi method. It was shown that the optimum levels of process parameters are: solution flow rate of $9 \mathrm{lit} / \mathrm{min}$, gas flow rate of $20 \mathrm{lit} / \mathrm{min}$, and solution concentration of $70 \mathrm{gr} / \mathrm{lit}$. Based on the ANOVA results, it was shown that the process parameters in terms of impact significance are gas flow rate, solution concentration, and solution flow rate. By using the optimum level of the process parameters, the production rate was enhanced by $168 \%$ in comparison to the mean value of the experimental results.

\section{ACKNOWLEDGMENT}

The authors thank the financial support of University of Tehran for this research.

\section{REFERENCES}

[1] C. Ramshaw and R. H. Mallinson, "Mass transfer process," U.S. Patent 4283255,1981

[2] S. Munjal, M. P. Dudukovic, and P. A. Ramachandran, "Mass transfer in rotating packed bedssI. Development of gas-liquid and liquid-solid mass transfer correlations," Chem. Eng. Sci., vol. 44, pp. 2245-2256, 1989.

[3] M. P. Kumar and D. P. Rao, "Studies on a high-gravity gas-liquid contactor," Ind. Eng. Chem. Res., vol. 29, pp. 917-920, 1990.

[4] P. Sandilya, D. P. Rao, A. Sharma, and G. Biswas, "Gas-Phase Mass Transfer in a Centrifugal Contractor," Ind. Eng. Chem. Res., vol. 40, pp. 384-392, 2001.

[5] Y. S. Chen and H. S. Liu, "Absorption of VOCs in a rotating packed bed," Ind. Eng. Chem. Res., vol. 41, pp. 1583, 2002.

[6] C. C. Lin, W. T. Liu, and C. S. Tan, "Removal of carbon dioxide by absorption in a rotating packed bed," Ind. Eng. Chem. Res., vol. 42, pp. 2381-2386, 2003.

[7] C. C. Lin, T. Y. Wei, W. T. Liu, K. P. Shen and J. Chem, "Removal of VOCs from gaseous streams in a high-voidage rotating packed bed," Eng. Jpn., vol. 37, 2004.

[8] C. S. Tan and J. E. Chen, "Absorption of carbon dioxide with bed," Separation and Purification Technology, vol. 49: pp. 174-180, 2006.

[9] H. H. Cheng, C. S. Tan, Reduction of $\mathrm{CO}_{2}$ concentration in a zinc/air battery by absorption in a rotating packed bed," Power Sources, vol. 162 , pp. 1431, 2006.

[10] C. C. Lin and G. S. Jain, "Characteristics of a rotating packed bed equipped with blade pickings", Sep. Purif. Technol., vol. 54, pp. 51-60, 2007.

[11] F. Guo, C. Zheng, K. Guo, Y. Feng, and N. C. Gardner, "Hydrodynamics and mass transfer in cross-flow rotating packed bed," Chem. Eng. Sci., vol. 52, pp. 3853, 1997.

[12] C. C. Lin, T. Y. Wei, S. K. Hsu, and W. T. Liu, Purif. Technol., Sep.2006, vol. 52, pp. 274.

[13] T. Kelleher and J. R. Fair, "Distillation studies in a high-gravity contactor," Ind. Eng. Chem. Res., vol. 35, pp. 4646, 1996.

[14] C. C. Lin, T. J. Ho, W. T. Liu, and J. Chem, "Distillation in a rotating packed bed," Eng. Jpn., vol. 35, pp. 1298, 2002.

[15] J. Peel, C. R. Howarth, and C. Ramshaw, Trans. Inst. Chem. Eng. Part A, vol. 76, pp. 585,1998

[16] Y. S. Chen, C. C. Lin, and H. S. Liu, "Mass transfer in a rotating packed bed with viscous Newtonian and non-Newtonian fluid," Ind. Eng. Chem. Res., vol. 44, pp. 1043, 2005.

[17] Y. S. Chen, C. C. Lin, H. S. Liu, "Mass Transfer in a Rotating Packed Bed with Various Radii of the Bed," Ind. Eng. Chem. Res., vol. 44, pp. $7868,2005$.

[18] Y. S. Chen, F. Y. Lin, C. C. Lin, Y. D. Tai, and H. S. Liu, "Packing characteristics for mass transfer in a rotating packed bed, "Ind. Eng. Chem. Res., vol. 45, pp. 6846, 2006.

[19] C. C. Lin, and W. T. Liu, J. Ind. Eng. Chem., vol. 13, pp. 71, 2007.

[20] M. Keyvani and N. C. Gardner, "Operating characteristics of rotating beds," Chem. Eng. Prog., vol. 85, pp. 48, 1989.
[21] S. P. Singh, J. H. Wilson, R. M. Counce, J. F. Villiers-Fisher, H. L. Jennings, A. J. Lucero, G. D. Reed, R. A. Ashworth, and M. G. Elliott, "Removal of volatile organic compounds from groundwater using a rotary air stripper," Ind. Eng. Chem. Res., vol. 31, pp. 574-580, 1992.

[22] H. S. Liu, C. C. Lin, S. C. Wu, and H. W. Hsu, "Characteristics of a bed," Ind. Eng. Chem. Res., vol. 35, no. 10, pp. 3590-3596, 1996.

[23] C. C. Lin, and W. T. Liu, "Removal of an undesired component from a valuable product using a rotating packed bed," J. Ind. Eng. Chem., vol. 12, pp. 455, 2006.

[24] C. C. Lin, W. T. Liu, and J. Chem, "Ozone oxidation in a rotating packed bed", Technol. Biotechnol., vol. 78, pp. 138, 2003.

[25] Y. H. Chen, C. Y. Chang, W. L. Su, C. C. Chen, C. Y. Chiu, Y. H. Yu, P. C. Chiang, and S. I. M. Chiang, "Modeling Ozone Contacting Process in a Rotating Packed Bed," Ind. Eng. Chem. Res., vol. 43, pp. 228, 2004.

[26] Y. H. Chen, C. Y. Chang, W. L. Su, C. C. Chen, C. Y. Chiu, Y. H. Yu, P. C. Chiang, C. F. Chang, J. L. Shie, C. S. Chiou, S. I. M. Chiang, and J. Chem, "Ozonation of CL reactive black 5 using rotating packed bed and stirred tank reactor," Technol. Biotechnol, vol. 80, pp. 68, 2005

[27] Y. H. Chen, C. Y. Chiu, C. Y. Chang, Y. H. Huang, Y. H. Yu, P.C Chiang, J. L. Shie, and C. S. Chiou, "Modeling ozonation process with pollutant in a rotating packed bed," Ind. Eng. Chem. Res., vol. 44, pp. 21, 2005.

[28] J. F. Chen, Y. H. Wang, F. Guo, X. M. Wang, and C. Zheng, "Synthesis of nanoparticles with novel technology: high-gravity reactive precipitation," Ind. Eng. Chem. Res., vol. 39, pp. 948, 2000.

[29] P. J. Ross, Taguchi Techniques for Quality Engineering, McGraw-Hill, New York, 1989.

[30] A. G. Diaz and D. T. Philips, Principles of Experimental Design and Analysis, Chapman \& Hall, London, 1995.

[31] D. C. Montgomery, Design and Analysis of Experiments, Wiley, New York, 2001

[32] D. R. Cox and N. Reid, The Theory of the Design of Experiments, Chapman \& Hall/CRC Press, London, 2000.

[33] M. S. Phadke, Quality Engineering Using Robust Design, Prentice Hall, Englewood Cliffs, NJ, 1989.

Gh. Tahmasebi Pour was born in Iran in 1974. He received the bachelor of science degree in mechanical engineering from the University of Tabriz, Tabriz, Iran, 1998, a master of science degree in mechanical engineering from the Amirkabir University of Technology, Tehran, Iran, 2001, and a $\mathrm{Ph} . \mathrm{D}$. degree in mechanical engineering from the Tarbiat Modares University, Tehran, Iran, 2009

$\mathrm{He}$ is an assistant professor in the Faculty of New Sciences and Technologies at the University of Tehran in Tehran, Iran. His research interests include nano science and technology, micro/nano-scale manufacturing technologies, MEMS/NEMS, nano-mechanics, synthesis and application of nano-materials, industrial nanostructures, composites and nanocomposites, multi-scale modeling and simulation, new manufacturing science and technologies, industrial automation, and mechatronics.

Dr. Tahmasebi Pour is a recipient of the TWAS prize to young scientists in 2011, 24th Khwarizmi International Award from Iranian Research Organization for Science and Technology (IROST) in 2011, certificate and gold medal from Economic Cooperation Organization (ECO) cultural institute in 2011. He ranked 2nd in the Tarbiat Modares University entrance exam for the Ph.D. degree in Iran, 2003, and ranked 3rd in the nationwide university entrance exam for the M.Sc. degree in Iran, 1998.

S. M. Mirzaee Moghadam was born in Iran in1986. He received the bachelor of science degree in mechanical engineering from the Islamic Azad University-Najafabad Branch, Najafabad, Iran in 2009, and a master of science degree in mechanical engineering from the Islamic Azad UniversityScience and Research Branch, Arak, Iran in 2013.

His research interests include nano science and technology, nanomaterials, nanocomposites, and manufacturing technologies. 